\title{
50th Congress of IPA in Buenos Aires
}

\section{Myounghwan Choi}

Naum Psychiatric Clinic, Daejeon, Korea

\section{아르헨티나 IPA 총회 참관기}

\section{최 명 환}

나음정신건강의학과

좋은 경험을 했다고 해도 그것을 전달하는 것이 쉽지 않 습니다. 제가 보고 느낀 것을 옮기는 것이지만 이게 쉽지 않 습니다. 참관기를 쓸 줄 알았으면 더 꼼꼼히 기록을 남겼더라 면 하는 후회도 들었습니다. 아는 것이 적으니 보고 느낀 것 도 적다는 하는 생각이 들었습니다. 남미가 워낙 멀고 여행자 도 많지 않아 여행 책자를 찾기도 쉽지 않았습니다. 그래도 뻔뻔하게 선입견이 없으니 객관적으로 봤겠거니 하는 마음 으로 편안하게 적어보았습니다.

\section{여 정}

International Psychoanalytical Association(IPA) 총회는 다음 모임일정을 2 년 전에 미리 알리기 때문에 참석 여부만 결정하면 일찍 여행 스케줄을 잡을 수 있습니다. 항공권은 예약이 빠를수록 이익이지요. 예약은 출발하기 9개월 전쯤 했습니다. 거리상 한 번에 가는 직항이 없어 경유하는 항공 편을 구매할 수밖에 없었습니다. 저는 달라스를 경유하는 비 행편을 예매했습니다. 등록하고 호텔도 여정에 맞게 예약하 는 등 모든 준비를 다 마쳤다고 생각했습니다. 미국에서 비 행기를 갈아타기 위해서 비자가 필요하다는 걸 몰랐던 것이 지요. 떠나기 전 우연하게 모임에서 학회 회원인 김민구 선생 님의 조언을 듣고서 겨우 일주일 남기고 비자 신청을 하게 되

Received: October 17, 2017

Address for correspondence: Myounghwan Choi, MD

Naum Psychiatric Clinic, 179 Daedeok-daero, Seo-gu, Daejeon 35230, Korea Tel: +82-42-472-2262, Fax: +82-42-472-2261

E-mail: macrospore@gmail.com

This is an Open Access article distributed under the terms of the Creative Commons Attribution Non-Commercial License (http://creativecommons.org/licenses/by-nc/4.0) which permits unrestricted non-commercial use, distribution, and reproduction in any medium, provided the original work is properly cited.
었습니다. 하마터면 달라스 공항에서 미아가 될 뼌했죠. 학 회에 가는 것을 자랑하기 싫다고 말하지 않고 있었으면 난 처할 뻔 했습니다. 아마 참관기 대신 고생기를 쓰고 있을지 도 모릅니다. 아르헨티나에 간다고 뻔뻔스럽게 떠벌린 덕에 무사히 갈 수 있었습니다. 오른손이 하는 일을 왼손이 모르 게 하라고 하셨지만 왼손의 도움으로 여정이 편안해질 수 있 었습니다. 환자를 볼 때에도 자랑이건 도움이건 동료와 경험 을 나누는 것이 도움이 되는 것처럼 여행 일정도 사람들과 나누는 것이 도움이 된다고 생각했습니다.

\section{아르헨티나의 인상}

사람들은 친절하고 여유 있고 편안해 보였습니다. 느긋한 걸음걸이, 여유 있는 태도, 밝은 표정의 사람들이 많았습니 다. 말을 걸 때 관심을 보이고 반응을 보이는 게 명확하니까 수줍음이 많은 저도 붙임성이 좋아지는 것 같았습니다. 학회 장인 Hilton호텔은 최근에 재개발된 깔끔한 곳이었습니다. 예전 항구에 군함 박물관과 좋은 식당들, 아름다운 풍경을 가 지고 있어서 많은 현지인이 주말을 즐기는 곳이었습니다. 사 람들은 유쾌하고 느긋하게 식사와 와인, 탱고를 즐기는 모습 이었습니다. 작은 공연을 하는 곳에 갔을 때 남녀노소 가리 지 않고 열정적으로 공연에 참여하는 모습이 인상적이었습 니다. 감정 표현에 적극적인데 부담스럽거나 과장되어 보이 지 않고 유쾌하고 멋있어 보였습니다. 학회장에서 만난 남미 의 분석가들도 비슷했습니다. 안타깝고 어려운 환자의 이야 기를 들으면 손짓, 발짓으로 안쓰러움을 표현하고 옆에 있는 저를 툭툭 치면서 “저 환자 참 불쌍하지 않니?”라고 스스럼없 이 말하는 모습이 인상적이었습니다. 유럽이나 미국 학회에 서 경험하기 힘든 일이었습니다. 어린 시절 동네에서 보던 어머니들 생각이 나 웃음이 나왔습니다. 이렇게 감정 표현이 


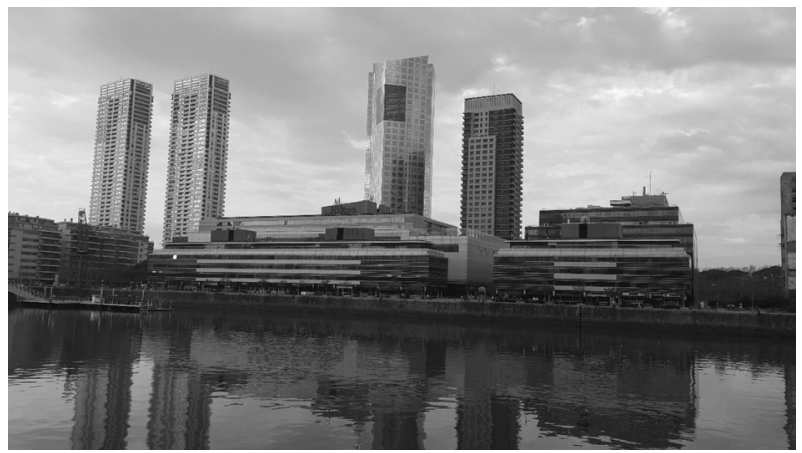

학회장이었던 부에노스아이레스의 힐튼 호텔(Buenos Aires Hilton)

적극적이고 자유로워서 그랬는지 학회장은 전반적으로 시끄 러웠고 discussion 시간에는 끼어들어 말하기도 어려웠습니 다. 다른 학회에서는 눈치 보다가 순서가 되면 수줍게 말하는 분들을 자주 보았는데 이곳에서는 말을 시키지 않아도 서로 서로 스페인어로 큰 소리로 이야기하는 분들이 많았습니다.

구 시가지는 멋있지만 낡아 보이는 버스나 지하철, 공항은 오래되고 정비를 잘 하지 못한 듯 했습니다. 나중에 현지인에 게 사회복지에 치중하면서 공공시설에 투자를 하지 못해서 공항과 길이 낡았다는 설명을 들을 수 있었습니다. 가정 경제 도 균형을 잡아야 하듯 국가 경제도 균형이 필요하다는 생각 이 들었습니다.

\section{학회 프로그램}

IPA는 등록할 때 여러 프로그램과 activity를 선택해서 등 록할 수 있습니다. 저는 couple therapy session과 discussion group, culture tour을 선택했습니다. Couple therapy는 따로 돈도 냈는데 막상 seminar 장소에서 등록 여부를 확인하지 않 고 참석할 수 있게 해서 참가비가 아까웠습니다. 대만 모임에 서 program committee로 같이 활동했던 호주의 Tim George 가 couple therapy session의 organizer였습니다. 저를 보더 니 반갑게 인사하고 토의 시간에 한국에서 왔다며 소개해 주 기도 했습니다. Couple therapy 시간 중 session을 비디오로 보여주는 시간이 가장 인상적이었습니다. 다른 치료자의 치 료를 본다는 것은 드문 경험이어서 열심히 보았습니다. 비디 오 자료에서 치료자는 가족들이 서로 상호 작용하는 것을 촉 진하고, 그것을 예민하게 관찰하고 분석해서 feedback을 주 는 역할을 하고 있었습니다. 가족의 interaction과 각 개인의 반응을 보면서 여러 생각들이 떠올랐습니다. 토의하는 시간 에 출신과 배경이 다른 참석자들이 비슷한 경험과 느낌을 가 졌다는 것을 확인할 수 있었습니다. 제가 생각하고 느끼는 것이 표준에서 크게 벗어나지 않았다는 것을 확인한 시간이 었습니다. 국제 학회에 참석해서 얻는 큰 이익 중의 하나는
자신이 치료에 대해 가지고 있는 견해와 관찰력이 국제적인 표준에 적합한지 확인할 수 있는 것입니다. 확인 결과 크게 다르지 않다면 제가 하고 있는 치료에 대한 자신감이 증가하 지요. 부족한 점을 보면 공부하고 노력해야 된다는 생각이 들고, 어떻게든 자신의 발전에 도움이 됩니다.

학회에서는 오전에 Keynote 발표가 있고 이후에 소 그룹으 로 discussion group이 열립니다. Discussion group은 오전에 발표되었던 Keynote에 대한 느낌을 나누고 정리하는 시간 입니다. 지난 보스턴 학회에서 discussion group에 참석해서 많은 도움을 받았습니다. 이번에도 미리 신청하고 참석했습 니다(미리 신청하지 않아도 들어가서 같이 할 수 있습니다). 작은 방에서 10 명 내외의 참석자들이 Instructor의 도움을 받 아 각자의 생각과 느낌을 이야기합니다. 아침에 들었던 강의 중에서 놓친 것을 다시 확인할 수 있고 새로운 생각을 서로 주고 받을 수 있어서 이번에도 매우 유익했습니다. Boston 학회 때는 발표 자료를 인터넷에서 미리 볼 수 있어서 내용 파악이 쉬었던 반면 이번에는 미리 볼 수 없어 아쉬웠습니 다. Discussion group에서 타국의 참석자들이 한국에 대해 관심 있어하고 많은 질문을 했습니다. 서구의 분석가들은 자 신과 다른 문화를 가진 곳에서 정신분석의 이론과 기법이 치 료에 통한다는 것을 흥미로워했습니다. 인상적인 것은 미국 의 분석가들 중 재미교포를 치료했던 분을 만났던 것입니다. 그분은 자신의 피분석가와 경험했던 일이 개인적인 피분석가 의 성향인지 한국 문화의 특성인지 궁금해했고 저를 만나 한 국에 대한 이야기를 듣게 된 것이 도움이 되었다고 했습니다.

이번 학회 발표 중 인상적인 것은 대부분의 발표자들이 Bion을 언급했다는 것이었습니다. 남미 분석가가 program committee에 많이 참여했고 그들의 이론이 Bion과 친밀한 영향도 있을 것 같았습니다. 혹은 요즈음 정신치료, 분석이 필요한 환자들을 Bion의 이론으로 이해해야 하니까 많이 언 급된 것인지 명확히 알기 어려웠습니다. Bion의 이론이 많이 언급된 것만큼 증례에서도 치료자가 무언가를 "해 주었다" 라고 말하는 경우가 많았습니다. 물론 치료적 환경을 만들어 주는 과정에 대한 이야기이긴 했지만 무언가를 해 주었다고 말하는 것이 이전보다 자유로워졌다는 느낌을 받았습니다. 전에는 그런 태도에 대해 중립성을 위배했다고 지적하시는 분도 있었는데 이번에는 잘 했다고 칭찬하는 이야기를 더 많 이 들었습니다. 찾아오는 환자들의 성향이 달라지면서(neurosis에서 PD로) 치료에서 더 많이 이용되고 적용하는 이론 도 유행을 타는 것 같다는 생각이 들었습니다. 어쨌거나 다 양한 이론을 공부하고 익숙해지는 것이 필요하다는 생각을 했습니다. 그리고 한국에 와서는 Bion에 관한 책을 한 권 사 게 되었습니다. 


\section{학회에서 한국}

매번 우리 학회의 위상이 높아지는 것을 실감합니다. 참석 하기도 어려웠던 이전과 달리 아르헨티나에서는 한 session 을 맡고 회원들이 발표를 하는 수준으로 성장했습니다. 고정 인, 노왕구, 정선주, 한성희 선생님이 각각 발표를 해 주셨고 유재학 선생님께서 좌장을 맡아주셨습니다. 시간이 부족해 서 충분히 토의하지 못했던 점과 방이 협소하고 참석자가 그리 많지 않았던 점이 아쉬웠습니다. 환자의 치료 과정에 대해서 더 깊게 토의할 시간이 부족한 점도 아쉬웠습니다. 하지만 짧은 시간이나마 우리의 위상을 높인 일이었다고 생 각되었습니다.

대만과 중국에서는 각각 1 명씩 참석했다고 합니다. 우리 학 회에서 11명이 참석했다고 하니 대만에서 온 Miming Yang 은 한국 group에서 많이 온 것이 부럽다고 했습니다. 우리가 지금처럼 열심히 노력하고 공부한다면 커가는 Asia-Pacific region에서 큰 역할을 맡을 수 있을 것 같습니다. 미래를 위 해서 눈을 열고 세계의 흐름을 놓치지 않기 위해 노력해야 된 다는 생각을 했습니다.

\section{후 기}

IPA 학회에 참석하는 것을 생각지도 못하던 시절 여러 선 생님의 학회 참관기를 보면서 많은 것을 느꼈습니다. 무엇보 다도 저도 학회에 참석하면 좋겠다고 생각했지요. 그저 바람 일 뿐이었습니다. 그런데 여러 선생님의 노력으로 우리 학회 의 위상이 높아지면서 IPA에 참석하는 것이 수월해졌습니
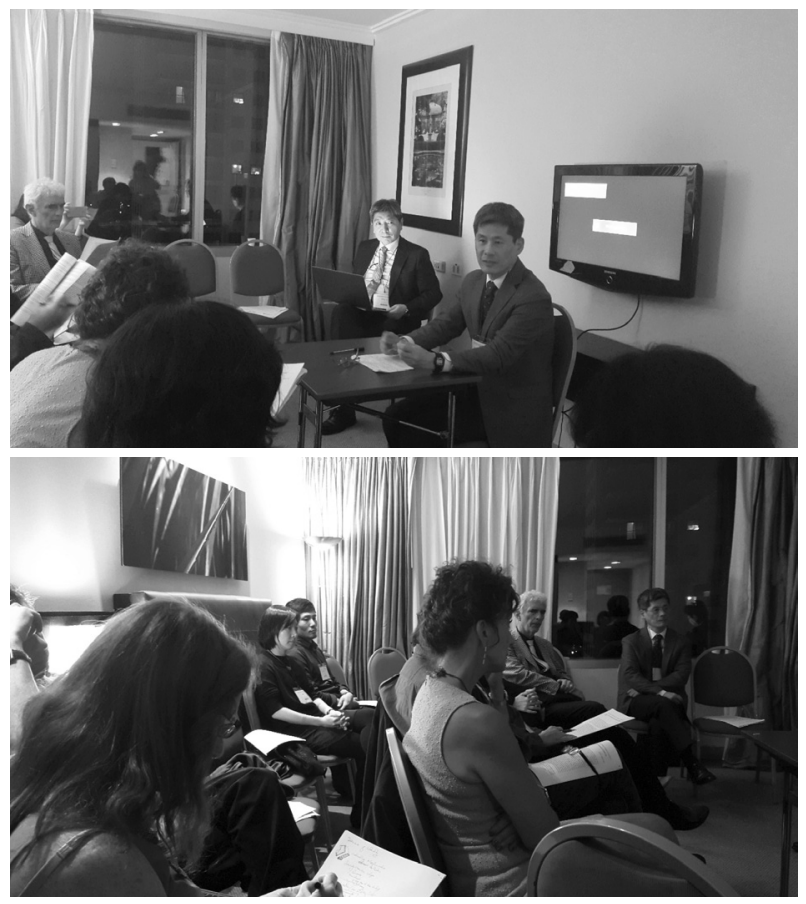

우리 학회가 주관한 발표 모습

다. 감사하고 기쁜 마음으로 참석했습니다. 이제는 공부하고 배움을 받는 수준이 아니라 우리의 경험을 나누고, 나아가 학 회를 주최하면 뭘 준비할까를 고민하는 수준으로 성장했습 니다. 성장에 따른 의무와 책임도 느껴지는 시간이었습니다. 바라건대 더 많은 분들이 IPA 학회에 참석하고 자기 발전과 우리 학회의 목소리를 더 높일 수 있는 기회를 가졌으면 좋겠 습니다. 